\title{
Stereology of the Neocortex in Odontocetes: Qualitative, Quantitative, and Functional Implications
}

\author{
A. Kern ${ }^{a} \quad$ U. Siebert ${ }^{b} \quad$ B. Cozzi ${ }^{\text {c }}$ P.R. Hof ${ }^{d}$ H.H.A. Oelschläger ${ }^{a}$ \\ aDepartment of Anatomy III (Dr. Senckenbergische Anatomie), Johann Wolfgang Goethe University, \\ Frankfurt am Main, and ${ }^{\mathrm{b}}$ Research and Technology Center Westcoast (FTZ), Christian Albrechts University of Kiel, \\ Büsum, Germany; ' Department of Experimental Veterinary Science, University of Padua, Padua, Italy; \\ ${ }^{\mathrm{d}}$ Department of Neuroscience and Friedman Brain Institute, Mount Sinai School of Medicine, New York, N.Y., USA
}

\section{Key Words}

Neocortex $\cdot$ Toothed whales $\cdot$ Odontocetes $\cdot$ Primary projection areas $\cdot$ Stereology $\cdot$ Harbor porpoise (Phocoena phocoena) $\cdot$ Bottlenose dolphin (Tursiops truncatus) . Evolution

\begin{abstract}
We investigated the quantitative morphology of the neocortex (gray matter) in 2 toothed whale (odontocete) species (harbor porpoise, Phocoena phocoena; bottlenose dolphin, Tursiops truncatus) with stereological methods. The 4 primary projection areas (motor, somatosensory, auditory, and visual fields) are analyzed for their cell densities in layers III and $\mathrm{V}$ with standard design-based stereology methods. Along cortical areas $\mathrm{M} 1, \mathrm{S1}, \mathrm{A} 1$, and $\mathrm{V} 1$ in Tursiops, neuron density is always higher in layer III than in layer $\mathrm{V}$, whereas the data in Phocoena are variable. Moreover, neuron density in layer III is generally around 1.5 times higher in Tursiops than in Phocoena. Maximal density values are seen in layer III of A1 and V1 in Tursiops and the ratio of layer III/layer V density is maximal in A1 of this species. Thus, layer III could have a higher capacity in the bottlenose dolphin with regard to intrinsic connectivity. Extant knowledge on toothed whale neurobiology and behavior suggests that quantitative/stereological differences between the 2 odontocete species regarding the
\end{abstract}

neuron density of standard cortical units may be correlated with specific adaptations to their respective habitats. In contrast to layers $\mathrm{V}$ and $\mathrm{VI}$ which mainly serve as an executive system, layer III could represent an intermediate level in sensory and premotor processing which works more tangentially in the cortices via horizontal connections with other cortical areas, respectively. The generally higher density of cortical layer III in Tursiops suggests a higher connectivity of this layer in view of the more agile and complicated behavior of these gregarious animals including versatile phonation by complex sound and ultrasound signals.

Copyright @ 2011 S. Karger AG, Basel

\section{Introduction}

As in many large-sized mammals, the neocortex is the dominant structure of the toothed whale (odontocete) brain and it is characterized by a remarkable folding of the gray matter. Although the gyral organization of the cerebral cortex shows many specific patterns in dolphins,

Dedicated to Dr. Heinz Stephan (formerly of the Max Planck Institute for Brain Research, Frankfurt am Main, Germany), eminent personality and role model in quantitative and comparative neurobiology. P.R.H. and H.H.A.O. are joint senior authors.

\section{KARGER}

Fax +41613061234

E-Mail karger@karger.ch

www.karger.com (c) 2011 S. Karger AG, Basel

0006-8977/11/0772-0079\$38.00/0

Accessible online at:

www.karger.com/bbe
Prof. Dr. H.A. Oelschläger

Department of Anatomy III (Dr. Senckenbergische Anatomie)

Johann Wolfgang Goethe University, Theodor Stern-Kai 7

DE-60590 Frankfurt am Main (Germany)

Tel.+49696301 6045, E-Mail Oelschlaeger@em.uni-frankfurt.de 
Fig. 1. Dorsal view of the brain of the bottlenose dolphin (T. truncatus) shows gyrification pattern of the neocortex with neocortical motor and sensory projection fields. Left half: fresh specimen (No. Marine 0082, Mount Sinai School of Medicine). Arrowheads mark the course of major neocortical sulci. Right half: schematic drawing, after Morgane et al. (1986). A1, A2 = primary, secondary auditory neocortex; $\mathrm{c}=$ cruciate sulcus; $\mathrm{Ch}=$ cerebellar hemisphere; en = entolateral sulcus; es = ectosylvian sulcus; la = lateral sulcus; $\mathrm{M} 1$ = motor neocortex; S1 = somatosensory neocortex; ss = suprasylvian sulcus; $\mathrm{V} 1$ = visual neocortex; $\mathrm{Ve}=$ vermis. Scale bar $=2 \mathrm{~cm}$.

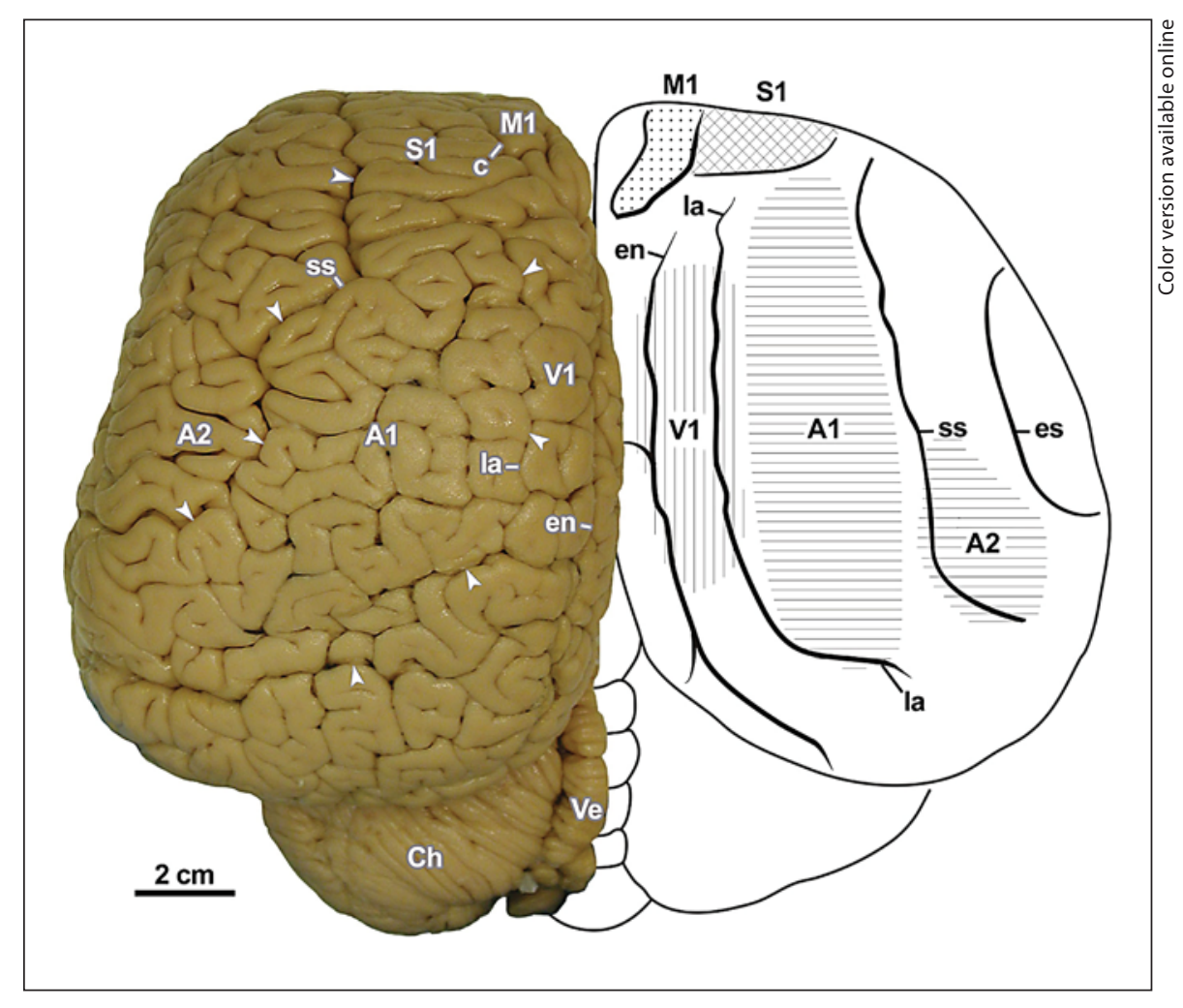

the sequence of the primary projection areas (motor, somatosensory, auditory, and visual fields) across the surface of the telencephalic hemisphere is similar to that in terrestrial mammals [Oelschläger and Oelschläger, 2002, 2009]. Electrophysiological experiments [Lende and Akdikmen, 1968; Lende and Welker, 1972; Ladygina and Supin, 1970, 1977; Ladygina et al., 1978; Supin et al., 1978, 2001] have shown that near the anteroventral tip of the cerebral hemisphere the motor and somatosensory cortical areas are separated by the cruciate sulcus, presumably a homolog of the central sulcus in primates [Morgane et al., 1980, 1986, 1990; Oelschläger and Oelschläger, 2002, 2009]. The auditory field is the largest primary projection area with the highest number of neurons and the largest cortical volume [Walloe et al., 2010; harbor porpoise, Phocoena phocoena; Eriksen and Pakkenberg, 2007; minke whale, Balaenoptera acutorostrata]. It is located in the suprasylvian and the posterior ectosylvian gyrus, bordering medially on the visual field which in toothed whales comprises the lateral gyrus adjacent to the interhemispheric cleft (fig. 1).

Still today, only little is known about the toothed whale neocortex. The cortical grey is 6-layered [Garey and Leuba, 1986; Deacon, 1990] as in other mammals. Earlier in- vestigators had often denied the existence of layer IV in the odontocete neocortex [Morgane et al., 1988; see below]. The overall thickness of the cortical grey is distinctly less in brains of toothed whales than in other brains of similar size [e.g. bottlenose dolphin: $1.2-1.85 \mathrm{~mm}$; human: 2.63 mm; Morgane et al., 1980, 1988; Ridgway and Brownson, 1984; Pakkenberg and Gundersen, 1997; Furutani, 2008]. Moreover, there is less regional cortical differentiation across the surface of the telencephalic hemisphere than in primates and other mammals and the layering of the cortical grey is less distinct because layer IV is reduced to 'insignificance' during the early postnatal years [Garey and Leuba, 1986] (fig. 2). This is an important fact and not well understood to date (see Discussion). In terrestrial mammals, layer IV receives major thalamic input and is particularly impressive in anthropoid primates. In their primary visual field, it is divided into 3 sublayers of small granular neurons and is involved in the complex processing of visual input [Hubel and Wiesel, 1968, 1972, 1977; Lund, 1973, 1984; Lund and Boothe, 1975; Nieuwenhuys, 1994].

In whales, dolphins, and porpoises (cetaceans; fig. 2), layer I (the molecular layer) is relatively thick and can comprise up to one third of the total cortical width. Lay- 


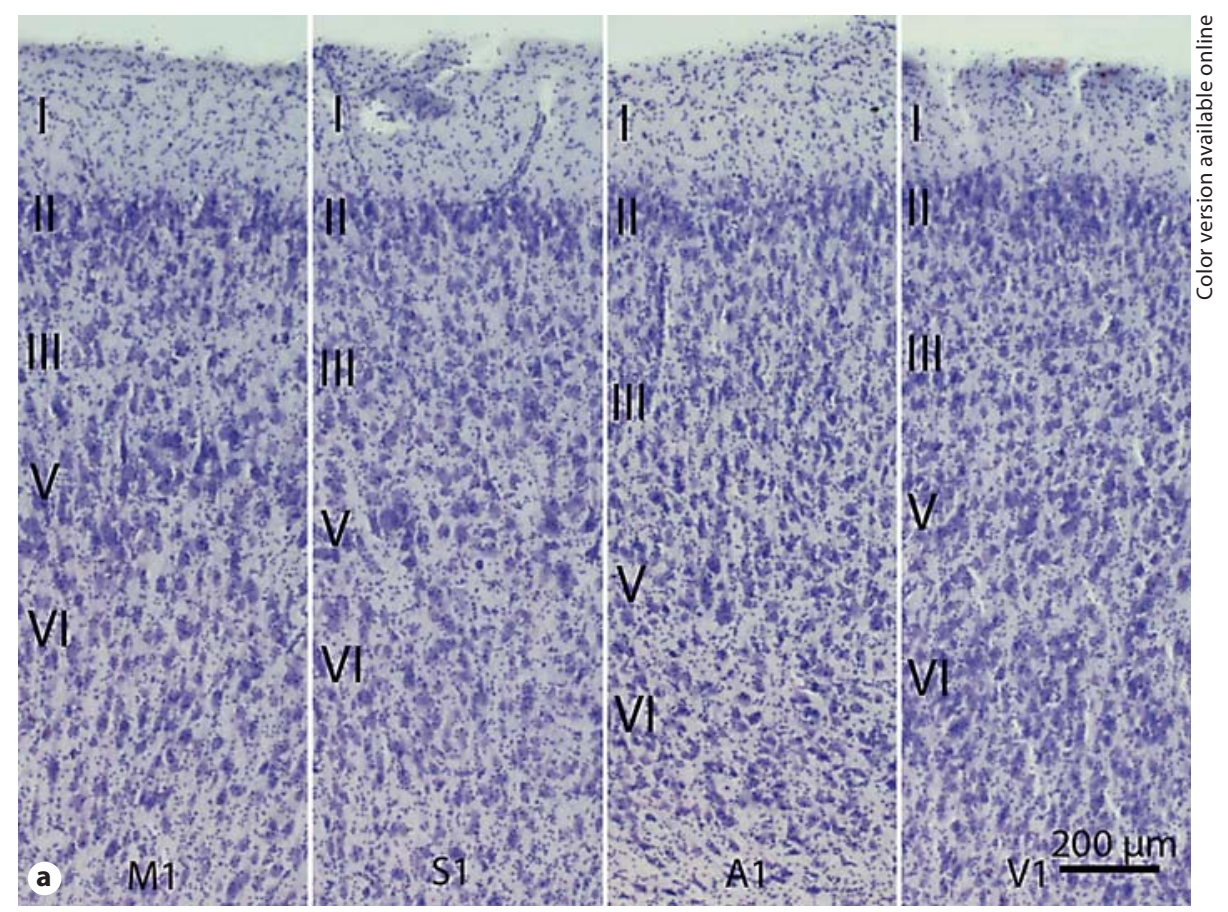

Fig. 2. Neocortical areas investigated. a Harbor porpoise. b Bottlenose dolphin. I to VI represent cortical layers. M1 = Motor; $\mathrm{S} 1$ = somatosensory; $\mathrm{A} 1$ = auditory; $\mathrm{V} 1=$ visual. Scale bars $=200 \mu \mathrm{m}$.
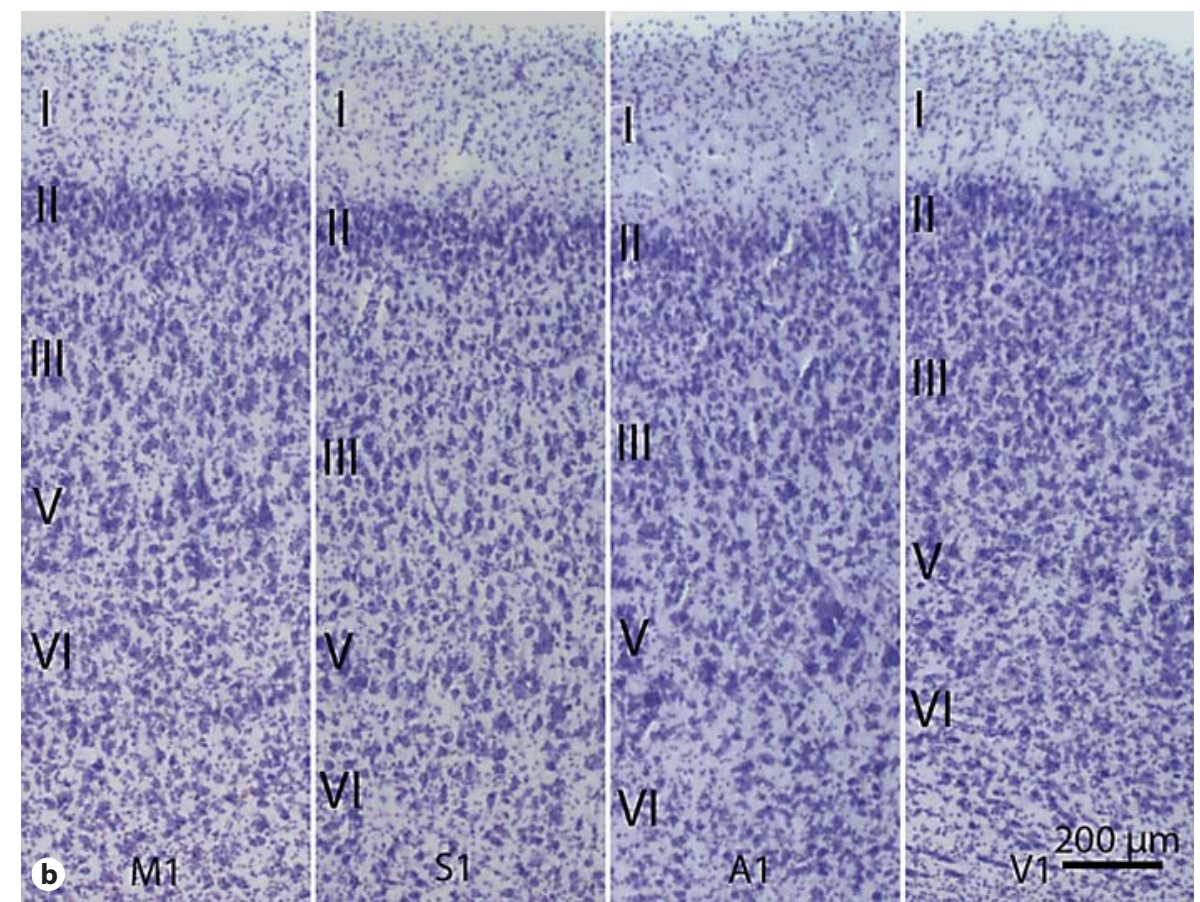

er II (the outer granular layer in terrestrial mammals) is thin but may show an apparently high neuron density among the cortical layers [e.g., visual cortex; Morgane et al., 1988]; these cells resemble small pyramidal neurons, some of which represent 'extraverted' neurons with subpial rather than basal dendrites. Layer III is comparative- ly thick and divided into 2 sublayers: an outer one with smaller pyramidal neurons and an inner sublayer with large to very large pyramids. With regard to possible remnants of layer IV in the adult toothed whale it is not clear whether such neurons have drifted into the neighboring layers (III and V). Layer V is much narrower than layer 
III and contains very large pyramidal cells which, however, may be challenged in size by those in layer III (inner sublayer) in some areas of the neocortex. Layer VI is well developed in toothed whales and often fades out in the white matter but may also adopt a columnar packing of neurons or even a cluster formation [Manger et al., 1998; Hof et al., 2005; Hof and Van der Gucht, 2007; Butti et al., 2009].

Interestingly, many specializations of the odontocete neocortex have been mistakenly interpreted as 'primitive' brain features ('initial brain' concept: poor lamination pattern, a thick layer I, extraverted pyramidal neurons in layer II, a dense band of large pyramidal neurons referred to as layer IIIc/V, overall weak granularization, and a well-developed layer VI) [Glezer et al., 1988]. One of the most striking deviations from terrestrial mammals is the overall strong pyramidalization of cortical neurons, which is in contrast to the general trend of a granularization of cortical neurons in primates [Garey and Leuba, 1986; Deacon, 1990]. It is doubtful, however, whether so many features can be called plesiomorphic in cetaceans, which have undergone dramatic structural and physiological modifications in order to adapt to their mode of a secondary fully aquatic life. It is thus more likely that the specific organization of the neocortex in cetaceans characterizes a highly adaptive neurobiological substrate which has to cope with the challenges resulting from the physical properties of their habitat.

As for the quantitative neuroanatomy of the toothed whale neocortex, it is difficult to compare our data with the results of existing papers because a variety of methods have been applied in the respective data acquisition. For an unbiased in-depth numerical analysis of the odontocete neocortex, we used here standard design-based stereology methods [optical fractionator, Cavalieri principle; Schmitz and Hof, 2005]. Our neuron counts in welldefined areas serve as a solid quantitative basis for a thorough comparison of 2 rather different odontocetes (harbor porpoise and bottlenose dolphin) with respect to ecophysiological and evolutionary implications.

Considering the differences in brain size and encephalization [Schwerdtfeger et al., 1984; Manger, 2006] and the differences in ecology, behavior, physiology, and acoustics [Marino et al., 2008; Bjorge and Tolley, 2009; Wells and Scott, 2009; Würsig, 2009] we were motivated to assess whether all these differences have a neurobiological correlate in the 2 species. We focused on the neocortex as it represents the superior level in the intellectual' contest of a species within its ecological niche. In this study, our main interest was to find the cortical piv- ot of functional and evolutionary changes in toothed whales during their adaptation to an aquatic environment. Considering the disappearance of layer IV in the cetacean cortex we decided to focus on the layer III/layer $\mathrm{V}$ horizon as a potential paradigm for understanding cortex functionality. We had the opportunity to investigate 2 toothed whale species different enough that we could look for potential correlations of quantitative cortex composition with the ecophysiology of the respective species.

In this paper, we investigate the primary neocortical areas of 2 odontocete species (harbor porpoise and bottlenose dolphin) which are only distantly related to each other. They more or less belong to the same dimension in terms of body size but show a number of differences in structure as well as in their behavior (table 1). One of the most fascinating differences is seen in the group size and dynamic group composition. Thus, bottlenose dolphins are usually found in groups of 2-15 animals or more (harbor porpoises: $1-3$ ) and show motor imitation, a large variety of sounds, and adult playful behavior, but they may also attack and kill porpoises [Würsig, 2009].

\section{Materials and Methods}

\section{Animals}

The 2 odontocete species investigated belong to separate families and differ in terms of body mass, brain mass, and potential ecological adaptations; the harbor porpoise is a dolphin-like toothed whale of moderate size with a relatively small brain (table 1) and moderate encephalization [Schwerdtfeger et al., 1984; Hof et al., 2005]; it lives in coastal habitats, emits polycyclic narrow-band sonar clicks between 119 and $128 \mathrm{kHz}$ with a source level of $191(\mathrm{~dB}$ re $1 \mu \mathrm{Pa})$, and has a frequency of best hearing around $130 \mathrm{kHz}$ [Ketten, 1998; Supin et al., 2001; Morisaka and Connor, 2007; Au and Hastings, 2008; Huggenberger et al., 2009]. The upper frequency limit (hearing) seems to be identical in the 2 species, with the maximum sensitivity ranging a little higher in the harbor porpoise. Major deviations in the widely distributed bottlenose dolphin are seen in the larger size of the body and brain and a higher encephalization, the emission of broad-band click sounds with higher source levels [218-228 ( $\mathrm{dB}$ re $1 \mu \mathrm{Pa})$ ], a much wider frequency range, and in the spectrum of best hearing in a lower frequency range.

The animals (Phocoena phocoena, PP 4417; Tursiops truncatus, TT 133) were by-caught (Phocoena) in the Northern Sea or died in a controlled environment. The brains were immersion-fixed in buffered $4 \%$ formaldehyde and the relevant cortical samples taken using brain maps drawn after experimental work by Ladygina and Supin [1970, 1977, 1978]. Neuropathological examination of the postmortem brains revealed no abnormalities in these specimens in either the macroscopic dimension or the microscopic dimension.

Before analysis of a high number of cortical samples a pilot study was made in order to optimize stereological parameters (ta- 
Table 1. Physical and physiological data of the harbor porpoise and the bottlenose dolphin

\begin{tabular}{|c|c|c|}
\hline Parameters & Harbor porpoise (PP) & Bottlenose dolphin (TT) \\
\hline Range of adult body length, cm & $130-180^{\mathrm{a}}$ & $227-340^{\mathrm{b}}$ \\
\hline Adult body length (investigated animal), $\mathrm{cm}$ & 138 & $250^{\mathrm{k}}$ \\
\hline Range of adult body mass, $\mathrm{kg}$ & $27-41$ & $140-278^{b}(\text { average } 165)^{\mathrm{c}}$ \\
\hline Adult body mass (investigated animal), $\mathrm{kg}$ & 41.7 & $200^{\mathrm{k}}$ \\
\hline Average adult brain mass, $g$ & 509.75 & $1,824^{\mathrm{c}}$ \\
\hline Encephalization ${ }^{\mathrm{d}}$ & 9.44 & 15.80 \\
\hline Habitat $^{\mathrm{e}}$ & shallow coastal & inshore, offshore \\
\hline Normal group size (individuals) ${ }^{1}$ & $1-3$ & $2-15$ \\
\hline Acoustic signals & clicks $^{\mathrm{f}}$ & clicks, whistles $^{\mathrm{f}}$ \\
\hline Echolocation clicks & narrow bandwidth ${ }^{\mathrm{f}}$ & broad bandwidth ${ }^{\mathrm{f}, \mathrm{g}}$ \\
\hline Frequency range (clicks), $\mathrm{kHz}$ & $119-128^{\mathrm{h}}$ & $35-132^{\mathrm{h}}$ \\
\hline Peak frequencies, $\mathrm{kHz}$ & $124^{\mathrm{h}}$ & $67-114^{\mathrm{h}}$ \\
\hline Peak-to-peak source level (clicks), dB re $1 \mu \mathrm{Pa}$ & $191^{\mathrm{h}}$ & $218-228^{\mathrm{i}}$ \\
\hline Frequency of best hearing, $\mathrm{kHz}$ & $130^{\mathrm{f}}$ & $60-80^{f, j}$ \\
\hline Upper frequency limit, $\mathrm{kHz}$ & $150^{\mathrm{f}}$ & $150^{\mathrm{f}}$ \\
\hline Maximum sensitivity, $\mathrm{dB}$ re $1 \mu \mathrm{Pa}$ & $47^{\mathrm{f}}$ & $42^{\mathrm{f}}$ \\
\hline \multicolumn{3}{|c|}{ 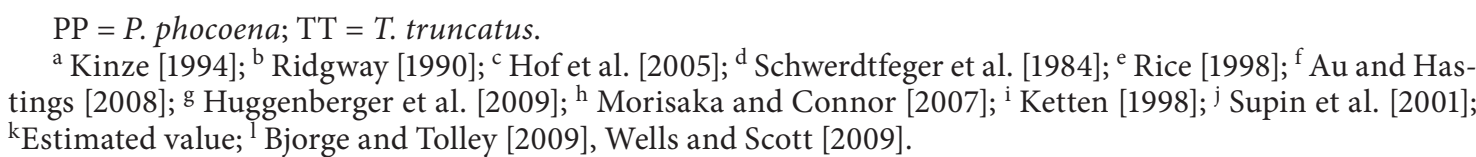 } \\
\hline
\end{tabular}

bles 2, 3). Samples were taken from the right cerebral hemisphere in both species according to the methodology of West et al. [1991; see also Schmitz and Hof, 2005]. A structural lateralization of the neocortex with respect to neuron numbers such as that found in some anthropoid primates has not yet been reported unequivocally for toothed whales [Poth et al., 2005]. The fact that we could only study 1 specimen of each of the 2 species relates to the very limited availability of toothed whale brain material suitable for stereological investigation. However, our data are consistent within the single cortical areas of our 2 animals (coefficient of error; table 4) and they correlate well with data in the literature on the bottlenose dolphin concerning both the total densities of cortical areas (auditory, visual) we investigated and the densities of layers III and V in these cortices [Garey and Leuba, 1986; Morgane et al., 1988, Eriksen and Pakkenberg, 2007; Walloe et al., 2010]. We analyzed only cresyl violet-stained sections from the cortex of these 2 animals which were of very good histological quality (fig. 2).

\section{Tissue Preparation}

We restricted our analyses to layers III and V of the primary neocortical fields [motor (M1), somatosensory (S1), auditory (A1), and visual field (V1)] as the regions of interest (ROI) in our specimens. In these areas, the first step in the cortical analysis of sensory input and the initiation of cortical output take place, and they are characterized by a maximum of structural differences in toothed whales. This is important for a reliable identification and definition of these areas within a rather uniform neocortex, in general, which is typical of odontocetes. On the other hand, these cortical areas in toothed whales most resemble the corresponding fields in other mammals, thus facilitating their comparison and evaluation with regard to functional and evolutionary aspects.

After fixation in $4 \%$ formaldehyde the cortical samples were dehydrated in graded concentrations of sucrose (10, 20, and 30\%), cut with a cryostat (Jung Histoslide 2000R, Leica, Germany) at a thickness of $60 \mu \mathrm{m}$, and stained with cresyl violet (Nissl stain). This led to a total between 68 and 109 sections for each cortical area (ROI).

\section{Stereological Design}

In order to obtain solid data for a future unbiased and exact comparison with other species, 2 state-of-the-art stereological methods, i.e. the optical fractionator [West et al., 1991] and the Cavalieri principle, were applied [Gundersen, 1986; Schmitz and Hof, 2005; Eriksen and Pakkenberg, 2007]. All of the quantitative analyses were performed using a stereology workstation equipped with a Zeiss Axiophot photomicroscope, $2.5 \times$ and $40 \times$ PlanNeofluar objectives (Zeiss, Thornwood, N.Y., USA), a motorized stage (Ludl Electronics, Hawthorne, N.Y., USA), an Optronics MicroFire digital camera (Optronics, Goleta, Calif., USA), and stereology software (StereoInvestigator; MBF Bioscience, Williston, Vt., USA).

The measurement of neuronal density values $\left(\mathrm{D}_{\mathrm{ROI}}\right)$ always depends on the ratio of a particle (neuron) count within a given ROI in relation to the volume of the respective ROI [Schmitz and Hof, 2005]. Combining the optical fractionator (for total cell counts, $\mathrm{N}_{\mathrm{ROI}}$ ) and the Cavalieri principle (for respective volumetric values, $\mathrm{V}_{\mathrm{ROI}}$ ), estimates of neuronal densities within specific 
Table 2. Synopsis of parameters used with the optical fractionator in the analysis of total neuron numbers

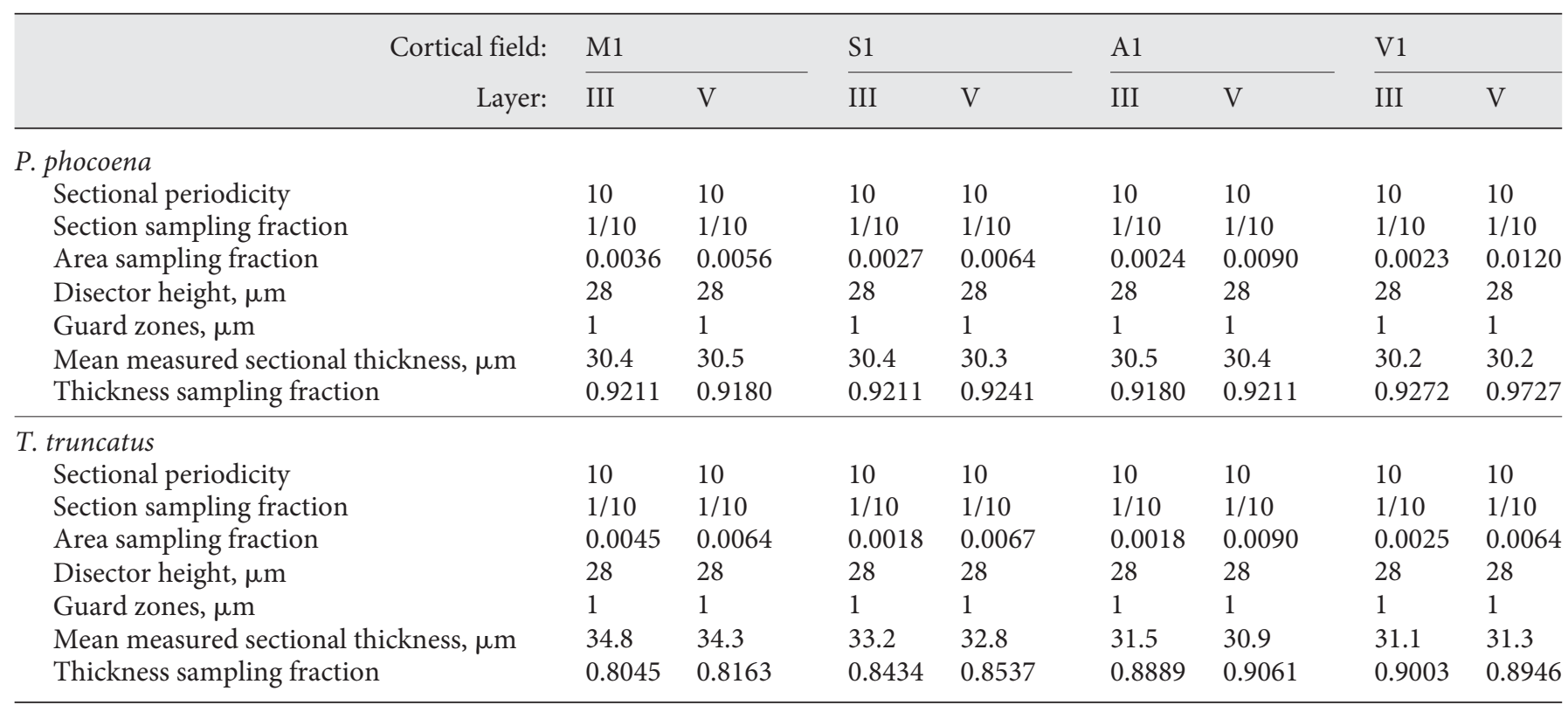

Table 3. Survey on parameters and data used with the Cavalieri method in the analysis of volumetric values

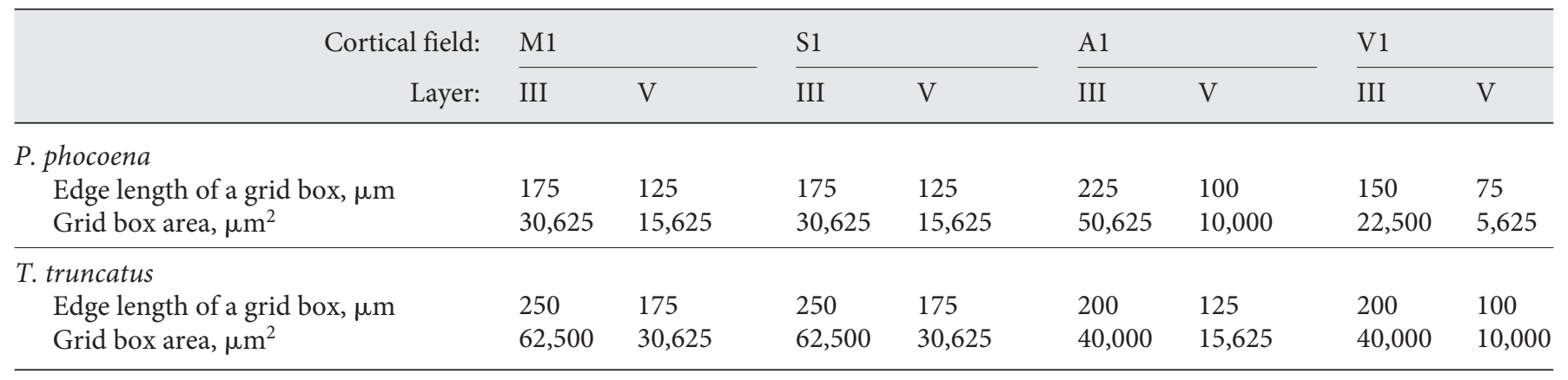

Table 4. Data on counting units (neuron numbers) and extrapolation with the optical fractionator

\begin{tabular}{|c|c|c|c|c|c|c|c|c|}
\hline \multirow{2}{*}{$\begin{array}{r}\text { Cortical field: } \\
\text { Layer: }\end{array}$} & \multicolumn{2}{|l|}{ M1 } & \multicolumn{2}{|l|}{ S1 } & \multicolumn{2}{|l|}{ A1 } & \multicolumn{2}{|l|}{ V1 } \\
\hline & III & $\mathrm{V}$ & III & $\mathrm{V}$ & III & $\mathrm{V}$ & III & $\mathrm{V}$ \\
\hline Total of counting units & 502 & 405 & 540 & 414 & 638 & 509 & 636 & 523 \\
\hline Coefficient of error & 0.042 & 0.042 & 0.032 & 0.038 & 0.026 & 0.036 & 0.026 & 0.031 \\
\hline Total of ROI neurons & $1,497,372$ & 783,265 & $2,150,556$ & 697,603 & $2,952,528$ & 613,365 & $2,970,805$ & 469,727 \\
\hline Coefficient of error & 0.040 & 0.048 & 0.045 & 0.048 & 0.034 & 0.031 & 0.033 & 0.035 \\
\hline Total of ROI neurons & $1,855,529$ & 606,007 & $3,494,258$ & 753,960 & $4,793,753$ & 965,593 & $4,418,817$ & 936,684 \\
\hline
\end{tabular}


Table 5. Data on ROI volumes calculated with the Cavalieri principle

\begin{tabular}{|c|c|c|c|c|c|c|c|c|}
\hline $\begin{array}{r}\text { Cortical field: } \\
\text { Layer: }\end{array}$ & III & $\mathrm{V}$ & III & $\mathrm{V}$ & III & $\mathrm{V}$ & III & $\mathrm{V}$ \\
\hline Total of counting units $(\Sigma n)$ & 6,290 & 4,449 & 7,144 & 4,402 & 4,434 & 6,179 & 8,858 & 7,527 \\
\hline ROI volume $\left(\mathrm{V}_{\mathrm{ROI}}\right), \times 10^{5} \mu \mathrm{m}^{3}$ & $1,155,790$ & 417,094 & $1,312,710$ & 412,687 & $1,346,830$ & 370,740 & $1,195,830$ & 254,036 \\
\hline ROI volume $\left(\mathrm{V}_{\mathrm{ROI}}\right), \times 10^{5} \mu \mathrm{m}^{3}$ & 917,625 & 332,220 & $1,514,620$ & 462,682 & $1,503,120$ & 509,531 & $1,083,360$ & 340,500 \\
\hline
\end{tabular}

Table 6. Neuron densities estimated with the optical fractionator and the Cavalieri principle

\begin{tabular}{|c|c|c|c|c|c|c|c|c|}
\hline \multirow{2}{*}{$\begin{array}{r}\text { Cortical field: } \\
\text { Layer: }\end{array}$} & \multicolumn{2}{|l|}{ M1 } & \multicolumn{2}{|l|}{ S1 } & \multicolumn{2}{|l|}{ A1 } & \multicolumn{2}{|l|}{ V1 } \\
\hline & III & $\mathrm{V}$ & III & $\mathrm{V}$ & III & $\mathrm{V}$ & III & $\mathrm{V}$ \\
\hline Total of ROI neurons $\left(\mathrm{N}_{\mathrm{ROI}}\right)$ & $1,497,372$ & 783,265 & $2,150,556$ & 697,603 & $2,952,528$ & 613,365 & $2,970,805$ & 469,727 \\
\hline ROI volume $\left(\mathrm{V}_{\mathrm{ROI}}\right), \times 10^{5} \mu \mathrm{m}^{3}$ & $1,155,790$ & 417,094 & $1,312,710$ & 412,687 & $1,346,830$ & 370,740 & $1,195,830$ & 254,036 \\
\hline ROI density $\left(\mathrm{D}_{\mathrm{ROI}}\right), \times 10^{6}$ cells $/ \mathrm{cm}^{3}$ & 12.96 & 18.78 & 16.38 & 16.90 & 21.92 & 16.54 & 24.84 & 18.49 \\
\hline Total of ROI neurons $\left(\mathrm{N}_{\mathrm{ROI}}\right)$ & $1,855,529$ & 606,007 & $3,494,258$ & 753,960 & $4,793,753$ & 965,593 & $4,418,817$ & 936,684 \\
\hline ROI volume $\left(\mathrm{V}_{\mathrm{ROI}}\right), \times 10^{5} \mu \mathrm{m}^{3}$ & 917,625 & 332,220 & $1,514,620$ & 462,682 & $1,503,120$ & 509,531 & $1,083,360$ & 340,500 \\
\hline ROI density $\left(\mathrm{D}_{\mathrm{ROI}}\right), \times 10^{6}$ cells $/ \mathrm{cm}^{3}$ & 20.22 & 18.24 & 23.07 & 16.30 & 31.89 & 18.95 & 40.79 & 27.51 \\
\hline
\end{tabular}

ROIs (i.e. layer III and V of the 4 primary cortical fields M1, S1, A1, and V1) could be calculated. Therefore, each neuronal cell count had to be divided by the respective cortical volume:

$$
\mathrm{D}_{\mathrm{ROI}}=\mathrm{N}_{\mathrm{ROI}} / \mathrm{V}_{\mathrm{ROI}}
$$

Details on the stereological parameters used for the optical fractionator and the Cavalieri principle are summarized in tables 2-6.

\section{Results}

\section{Quantitative Analysis of Odontocete Neocortical}

Projection Areas

Neuron density varies considerably throughout the odontocete neocortex from area to area [Garey and Leuba, 1986] and across layers I to VI. Layer I is comparatively broad in whales, where it can comprise about one third of the total cortical grey width [Kraus and Pilleri, 1969a; Oelschläger and Oelschläger, 2002, 2009] and shows about $10-18 \%$ of the neuron density found in layer II [mean adult 13\%: Garey and Leuba, 1986; 6.44\%: Mor- gane et al., 1988; see below]. However, due to the small amount of neurons in layer I it was not analyzed stereologically in this study. Layer II is characteristic and uniform throughout the areas investigated but the neurons are difficult to analyze properly because of their extremely high packing density. The latter seems to be relatively constant and layer II has been reported to account for at least $50 \%$ of the total neocortical neuron number [Garey and Leuba, 1986; Oelschläger and Oelschläger, 2002, 2009].

In our study, we focused on layers III and V (tables 2-6) because they appear to be essential in the processing of thalamic and intracortical information and because they are well developed, easy to identify, and can be analyzed reliably. However, there seems to be some variation in cetaceans in terms of the density of neurons constituting a potential layer IV. Whereas in the literature on odontocetes the neuron density in layer IV was reported to attain more than $20 \%$ of that seen in layer III [visual field; bottlenose dolphin; Morgane et al., 1988], we could not detect layer IV throughout our materials. Kraus and 
Table 7. Stereology of neuron densities in layers III and V of the primary neocortical areas in the harbor porpoise ( $P$. phocoena) and the bottlenose dolphin (T. truncatus)

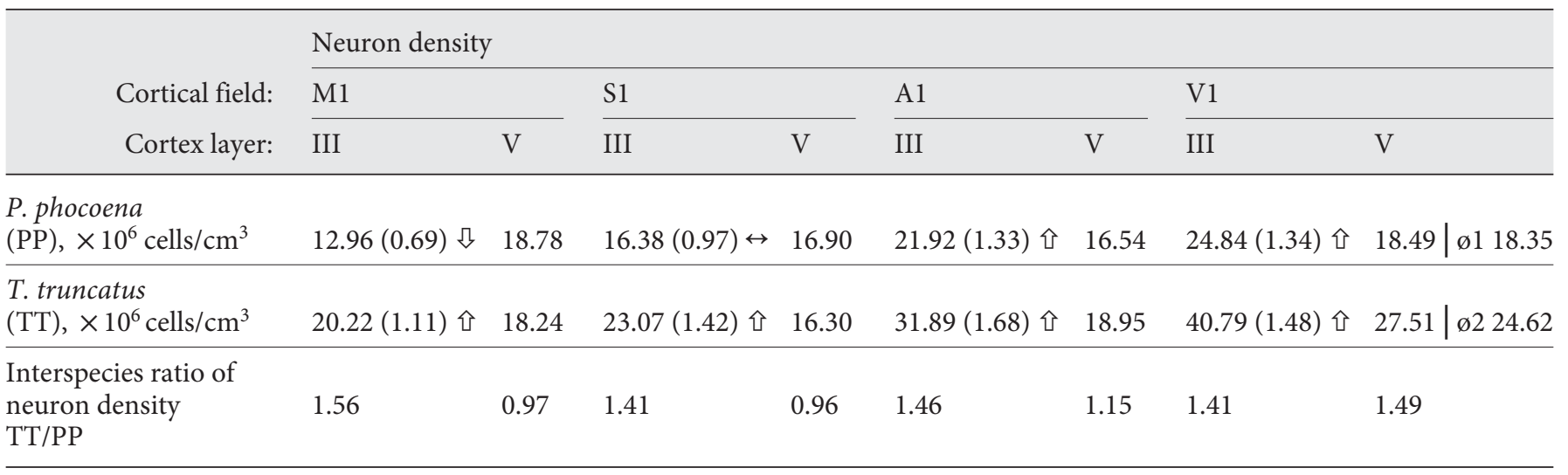

Numbers in parentheses indicate the layer III/layer V ratio in 1 area of 1 species. Arrows indicate trends in the ratios of layer III/V. The interspecies ratio in neuron density refers to the value of $\mathrm{PP}=1$. 仓 $=$ Higher; $\Omega=$ lower value than in layer $\mathrm{V}$ of the same area; $ø 1$ = average of layers III and V in Phocoena; $\varnothing 2$ = average of layers III and V in Tursiops throughout all neocortical areas.

Pilleri [1969a, b] also reported a layer IV with an appreciable neuron density in both the pilot whale (Globicephala melas) and the fin whale (Balaenoptera physalus) but, unfortunately, did not present any routine (Nissl stain) histology. In our specimens, layer III is thick and characterized by a variety of pyramidal cells with comparatively smaller neurons populating the outer half of the layer, whereas larger pyramids occupy the inner half. Layer $\mathrm{V}$ consistently contains large to very large pyramidal cells which form a distinct band. Layer VI fades out gradually into the white matter and therefore cannot be delimited unequivocally.

Our results, summarized in table 7 , include a number of interesting features:

(1) Comparing layers III and V within both species along cortical areas $\mathrm{M} 1, \mathrm{~S} 1, \mathrm{~A} 1$, and $\mathrm{V} 1$, neuron density in Tursiops is always higher in layer III than in layer V, whereas the data in Phocoena are variable. Thus, in M1 of Phocoena cell density is higher in layer V than in layer III, whereas in S1 the values are nearly identical and layer III neuron density dominates in A1 and V1.

(2) In our samples, the values for layer III of areas M1, S1, A1, and V1 are generally around 1.5 times higher in Tursiops than in Phocoena; this ratio is equaled by that found for layer V of V1 in the 2 species (see Discussion). The neuron density in layer $\mathrm{V}$ of $T$. truncatus is generally about as high as, or higher than, in P. phocoena (table 7), with a distinct increase in this ratio in V1. The largest difference between the 2 animals in terms of neuron density is seen in layer III of the motor cortex (ratio 1.56), the smallest in layer V of M1 and S1 (ratio 0.97 vs. 0.96, respectively).

(3) The overall minimum in neuron density is found in layer III of M1 in the harbor porpoise, and the overall maximum is found in layer III of V1 in the bottlenose dolphin. At the same time, the neuron density of layer III dominates that of layer $\mathrm{V}$ maximally in Al of Tursiops (ratio 1.68). In the bottlenose dolphin, maximal density values are seen in areas $\mathrm{A} 1$ and V1 and the ratio layer III/ layer $\mathrm{V}$ is maximal in area $\mathrm{A} 1$. Interestingly, layer III shows about the same range in both species (Phocoena 1: 1.92; Tursiops 1:2.02) but layer $\mathrm{V}$ does not.

Taken all together, layer III seems to be more complicated than layer $\mathrm{V}$ in both odontocete species, but this occurs on a much higher level and more consistently in the bottlenose dolphin than in the harbor porpoise.

\section{Discussion}

\section{General Considerations}

Although a number of papers have dealt with the quantitative morphology of the cetacean neocortex [Tower, 1954; Hawkins and Olszewski, 1957; Kraus and Pilleri, 1969a; Rockel et al., 1980; Morgane et al., 1982; Jacobs et al., 1984, Garey et al., 1985; Garey and Leuba, 1986; Haug, 1987; Poth et al., 2005; Eriksen and Pakkenberg, 2007; Butti et al., 2009; Oelschläger et al., 2010; Walloe et al., 2010], our knowledge of it is still rather limited. Brains differ in size and cortical thickness; larger animals with- 
in a systematic group tend to have larger brains with a more convoluted cortex and a slightly thicker cortical grey but a lower number of subpial neurons [Haug, 1987; Poth et al., 2005] and also a lower neuron density [Tower, 1954; Rockel et al., 1980; Eriksen and Pakkenberg, 2007; Oelschläger and Oelschläger, 2002, 2009]. Poth et al. [2005], counted neurons below a standard (pial) surface in order to eliminate differences in cortical thickness in the comparison of various species within an 'ascending toothed whale series' with increasing body mass and brain mass as a parallel to the 'ascending primate series' [Stephan, 1975; Schwerdtfeger et al., 1984; Matano et al., 1985; Stephan et al., 1988; West, 1990; Oelschläger et al., 2010].

In the past, most of the publications on the quantitative neuroanatomy of the cetacean neocortex provided data on the total neuron number throughout all layers of cortical samples [Tower, 1954; Rockel et al., 1980; Poth et al., 2005; Eriksen and Pakkenberg, 2007]. These papers reported comparatively low neuron counts in cetaceans in general [Oelschläger and Oelschläger, 2002, 2009] and a general pyramidalization and loss of granular cells perhaps in view of rapid sound processing using an apparently 'simple' kind of neocortical cytoarchitecture [Huggenberger, 2008]. A few investigators went into more detail and determined the dimensions and composition of single layers in the limbic lobe and the visual cortex of dolphins and other toothed whales [Kraus and Pilleri, 1969a; Garey and Leuba, 1986; Morgane et al., 1982, 1988, 1990; Furutani, 2008]. The comparative interpretation of all of the data provided, however, is difficult because it is limited by differences in methodology in these papers. Recently, Schmitz and Hof [2005] reviewed the literature that introduced the principles of design-based stereology and provided guidelines for efficient and rigorous quantitative neuroanatomical investigations. This allows accurate analyses of well-defined cortical units and their components including the comparison of such parameters in various mammals.

Another problem in the analysis of the cetacean cortex is the functional interpretation of the data received by stereological analysis. Here, we have to focus on the parts where adaptive processes are most obvious, i.e. components or strata differing maximally from those in terrestrial mammals. From a neurophysiological point of view, the boundaries of layer IV (inner granular layer) together with the neighboring layers III and V are pivotal in understanding odontocete neocortex evolution. In many terrestrial mammals, this layer largely hosts small multipolar interneurons [stellate cells; Lund 1984], which are regarded as a major target of specific thalamocortical afferents [Hubel and Wiesel, 1968, 1972, 1977; Lund, 1973; Jones, 1975, 2009; Lund and Boothe, 1975; White, 1978, Garey and Leuba, 1986; Nieuwenhuys, 1994, 1998]. Also, because in cetaceans the transition from layer III to layer $\mathrm{V}$ is somehow gradual, it seems reasonable to focus on these 2 layers, which in terrestrial mammals represent a basic input-output neocortical circuit [Valverde, 1983; Linden and Schreiner, 2003] with potentially multipolar cells being intercalated between the afferent cortical nerve fibers and the layer $\mathrm{V}$ pyramidal cell axons.

Histochemical investigation of the visual neocortex in the cat revealed strong cytochrome oxidase activity in layer IV [Wong-Riley, 1979; Wong-Riley and Carroll, 1984]. In the bottlenose dolphin and harbor porpoise, this activity is divided into 2 sheets, i.e. one in the upper half of layer I and the other in layer III [Revishchin and Garey, 1991]. This may indicate that thalamocortical input into the cetacean neocortex was shifted to layers I and III [Deacon, 1990; Furutani, 2008]. The cetacean neocortical layers III and V are well developed, consist mainly of middle-sized to large pyramids, and host some very large pyramids in M1 but sometimes also in A1 [Kern et al., unpubl. data]. Layer III is divided into an outer sublayer and an inner sublayer (and sometimes even 3 sublayers) [visual cortex; Morgane et al., 1988]. Whereas the outer sublayer comprises smaller pyramids, the inner sublayer hosts large pyramidal neurons which, in the auditory cortex, may be even larger than those in layer $\mathrm{V}$ [finless porpoise: Neophocaena phocaenoides; Delphinus, Tursiops; Kern, unpubl. data]. In our bottlenose dolphin specimen, neuron density was higher in layer III than in layer $\mathrm{V}$ throughout all of the neocortical areas investigated, in contrast to the more or less ambiguous situation found in the harbor porpoise. Our results are in good numerical correspondence with those of density calculations for V1 in the bottlenose dolphin by Garey and Leuba [1986] and Morgane et al. [1988]. Eriksen and Pakkenberg [2007] also found neuron densities to be higher in the visual cortex than in the auditory cortex of the minke whale, a small baleen whale species. Concerning our other data shown in table 7, the generally higher neuron densities in layer III of the bottlenose dolphin compared to the harbor porpoise throughout all of the cortical areas examined (table 7) may correlate with specific adaptations with regard to sensory and locomotor activity in the more versatile Tursiops versus the more specialized Phocoena, respectively (see below). 
Ecophysiological Adaptations of the Odontocete Neocortex

Our results indicate that there may exist correlations between stereological neocortical parameters and the lifestyle of the 2 species investigated (harbor porpoise and bottlenose dolphin). This is remarkable with respect to the consistently higher density of layer III neurons in all primary neocortical areas of T. truncatus compared to those in P. phocoena. Interestingly, this phenomenon is in obvious contrast to the well-known allometric effects of (a) decreasing neuron numbers per cortical unit, i.e. below a standardized area of neocortical surface [Poth et al., 2005], and (b) decreasing cortical neuron density, respectively, in mammals with increasing brain mass [Manger, 2006; Oelschläger and Oelschläger, 2002, 2009; Oelschläger et al., 2010]. Our data show generally higher neuron numbers per layer III volume unit in $T$. truncatus than in P. phocoena (see Results), and maximal densities were seen in areas A1 and V1. At the same time, Tursiops exhibits a considerably higher amount of neocortex [Manger, 2006] than the harbor porpoise and the brain as a whole is distinctly larger in Tursiops with respect to the total body mass of the animal (higher encephalization; table 1). Moreover, larger brains tend to have higher percentages of neocortex in the total brain [Oelschläger and Oelschläger 2009], higher percentages of white matter in the neocortex [telencephalic hemispheres; Oelschläger et al., 2010], and thus lower percentages for the cortical grey. All of these data seem to imply a higher cortical connectivity/plasticity for T. truncatus across an absolutely and relatively larger neocortical area in an animal of considerable encephalization. However, the data available do not allow direct comparison of the cortical fraction in the total brain in the harbor porpoise and the bottlenose dolphin. In contrast to layers $\mathrm{V}$ and VI which mainly serve as an executive system feeding subcortically into nonspecific and specific thalamic nuclei as well as into the tectum (inferior colliculus), medulla oblongata, and spinal cord [Nieuwenhuys, 1998], layer III could represent an intermediate level in sensory and premotor processing, which works more tangentially (associatively) in the cortices via '...extending longrange lateral projections to form horizontal connections with other cortical columns' [Linden and Schreiner, 2003]. Layer III may thus be involved in integrative processes covering the generation of complicated sound signals for communication (whistles) as well as quick and sophisticated swimming maneuvers in response to manifold ultrasound (echolocation) and sound patterns [audiomotor navigation; Oelschläger, 2008]. As a conse- quence, the generally higher density of cortical layer III in the bottlenose dolphin suggests a higher connectivity of this cortical layer in this species in view of the higher activity shown in more agile and complicated behavior, and this seems to hold true for all of the neocortical areas investigated. Interestingly the auditory neocortex, although it is the primary cortical field of the dominant sensory system in cetaceans, does not exhibit a particularly high layer III neuron density. In fact, the layer III neuron density in the auditory cortex is second to that in the visual cortex; this is presumably because in the auditory system most of the sensory processing occurs in the subcortical structures [inferior colliculus; Ehret, 1997; Linden and Schreiner, 2003], in contrast to the situation in the visual system. Thus, whereas '...the auditory cortex (most obviously) receives binaural input from subcortical nuclei..., the primary sensory cortex (visual and somatosensory systems) represents the earliest neural station for the convergence of inputs from the 2 visual hemifields or 2 sides of the body [Linden and Schreiner, 2003].

From our data it is evident that the odontocete neocortex has undergone profound structural and functional adaptations to meet the physical demands of the aquatic environment. This may appear in the general predominance of pyramidal neurons and the considerable reduction of layer IV which was detected in smaller toothed whales by Garey and Leuba [1986] as a residue in young postnatal animals. The differences between the primary neocortical areas in the 2 smaller odontocete species investigated here concerning the stereology of layers III and $\mathrm{V}$ are obviously correlated with specifics of their respective habitats and behavioral characteristics. Thus, for example, dolphins living in the open sea (T. truncatus) have large eyes collecting more visual information than those of coastal porpoises ( $P$. phocoena) and so-called 'river' dolphins which live in murky waters and have smaller eyes and less developed or even markedly reduced visual systems [Schwerdtfeger et al., 1984]. Apart from that, social life and thus acoustic communication seem to be more intense and therefore more complicated in rather gregarious bottlenose dolphins and other off-shore dolphins than in coastal porpoises or riverine dolphins which live singly or in very small groups (table 1). Whereas bottlenose dolphins are extremely versatile in terms of sound production with regard to the complexity and bandwidth of their signals (clicks and whistles), harbor porpoises seem to generate clicks for both orientation and communication [Huggenberger et al., 2009]. Within their ecological niche, this single-type high-frequency phona- 
tion of porpoises may be understood as a strategy to prevent killer whale predation [Morisaka and Connor, 2007] by avoiding low-frequency signals audible for these animals.

\section{Acknowledgments}

The authors sincerely thank Camilla Butti, Malin Hoistad, William G.M. Janssen, and Bridget Wicinski (Mount Sinai School of Medicine, New York, N.Y., USA) for their generous help and advice. Stefan Huggenberger (Cologne, Germany) kindly advised us with regard to sensory abilities and the behavior of harbor porpoises and bottlenose dolphins. We are indebted to Jutta S. Oel- schläger for her excellent technical assistance. The continuous support of our work by Jörg Stehle (Institute of Anatomy III, Dr. Senckenbergische Anatomie, Frankfurt am Main) is gratefully acknowledged. This project was sponsored in part by the James $\mathrm{S}$. McDonnell Foundation (grant 22002078 to P.R.H.) and by Dr. Senckenbergische Stiftung Frankfurt am Main, Germany (H.H.A.O.). This work would not have been possible without travel funding by the Deutscher Akademischer Austauschdienst (DAAD, Bonn, Germany) in cooperation with the International Academy of Life Sciences, Inc. (Ellsworth, Me., USA, and Hannover, Germany).

The authors are also grateful to Hilmar Stolte (Hannover Medical School) for his effort concerning the BMEP. The chief editor of this journal and two anonymous referees are thanked for valuable comments on this paper.

\section{References}

Au WWL, Hastings MC (2008): Principles of Haug H (1987): Brain sizes, surfaces, and neuroMarine Bioacoustics. New York, Springer.

Bjorge A, Tolley KA (2009): Harbor porpoise Phocoena phocoena; in Perrin WF, Würsig B, Thewissen JGM (eds): Encyclopedia of Marine Mammals, ed 2. San Diego, Academic Press, pp 530-532.

Butti C, Sherwood CC, Hakeem AY, Allman JM Hof PR (2009): Total number and volume of Von Economo neurons in the cerebral cortex of cetaceans. J Comp Neurol 515:243-259.

Deacon TW (1990): Rethinking mammalian brain evolution. Am Zool 30:629-705.

Ehret G (1997): The auditory midbrain, a 'shunting yard' for acoustical information processing; in Ehret G, Romand R (eds): The Central Auditory System. New York, Oxford University Press, pp 259-316.

Eriksen N, Pakkenberg B (2007): Total neocortical cell number in the mysticete brain. Anat Rec 290:83-95.

-Furutani R (2008): Laminar and cytoarchitectonic features of the cerebral cortex in the Risso's dolphin (Grampus griseus), striped dolphin (Stenella coeruleoalba), and bottlenose dolphin (Tursiops truncatus). J Anat 213:241-248.

- Garey LJ, Leuba G (1986): A quantitative study of neuronal and glial numerical density in the visual cortex of the bottlenose dolphin: evidence for a specialized subarea and changes with age. J Comp Neurol 247:491-496.

- Garey LJ, Winkelmann E, Brauer K (1985): Golgi and Nissl studies of the visual cortex of the bottlenose dolphin. J Comp Neurol 240:305321.

Glezer II, Morgane PJ, Jacobs MS (1988): Implications of the 'initial brain' concept for the brain evolution in Cetaceans. Behav Brain Sci 11:75-116

-Gundersen HJG (1986): Stereology of arbitrary particles: a review of unbiased number and size estimators and the presentation of some new ones, in memory of William R. Thompson. J Microsc 143:3-45. nal sizes of the cortex cerebri: a stereological investigation of man and his variability and a comparison with some mammals (primates, whales, marsupials, insectivores and one elephant). Am J Anat 180:126-142.

-Hawkins A, Olszewski J (1957): Glia/nerve cell index for cortex of the whale. Science 126 : 76-77.

Hof PR, Chanis R, Marino L (2005): Cortical complexity in cetacean brains. Anat Rec 287: 1142-1152.

Hof PR, Van der Gucht E (2007): Structure of the cerebral cortex of the humpback whale, Megaptera novaeangliae (Cetacea, Mysticeti, Balaenopteridae). Anat Rec 290:1-31.

Hubel DH, Wiesel TN (1968): Receptive fields and functional architecture of monkey striate cortex. J Physiol 195:215-243.

Hubel DH, Wiesel TN (1972): Laminar and columnar distribution of geniculo-cortical fibers in the macaque monkey. J Comp Neurol

Hubel DH, Wiesel TN (1977): Ferrier lecture: functional architecture of macaque monkey visual cortex. Proc R Soc Lond B Biol Sci 198: $1-59$.

Huggenberger S (2008): The size and complexity of dolphin brains - a paradox? J Mar Biol Assoc UK 88:1103-1108.

-Huggenberger S, Rauschmann MA, Vogl T, Oelschläger HHA (2009): Functional morphology of the nasal complex in the harbor porpoise (Phocoena phocoena L.). Anat Rec 292: 902-920.

- Jacobs MS, Galaburda AM, McFarland WL, Morgane PJ (1984): The insular formations of the dolphin brain: quantitative cytoarchitectonic studies of the insular component of the limbic lobe. J Comp Neurol 225:396432.

Jones EG (1975): Lamination and differential distribution of thalamic afferents within the sensory-motor cortex of the squirrel monkey. J Comp Neurol 160:167-203. 146:421-450
Jones EG (2009): Synchrony in the interconnected circuitry of the thalamus and cerebral cortex. Ann NY Acad Sci 1157:10-23.

Ketten DR (1998): Marine Mammals Auditory Systems: A Summary of Audiometric and Anatomical Data and Its Implications for Underwater Acoustic Impacts. Boston, NMFS.

Kinze CC (1994): Phocoena phocoena (Linnaeus, 1758) - Schweinswal oder Kleintümmler; in Niethammer J, Krapp F (eds): Handbuch der Säugetiere Europas, Meeressäuger (vol 6, Teil I A): Robineau D, Duguy R, Klima M (eds): Wale und Delphine - Cetacea. Wiesbaden, Aula, pp 242-264.

Kraus C, Pilleri G (1969a): Quantitative Untersuchungen über die Großhirnrinde der Cetaceen; in Pilleri G (ed) Investigations on $\mathrm{Ce}$ tacea. Berne, Institute of Brain Anatomy, vol $1, \mathrm{pp}$ 127-150.

Kraus C, Pilleri G (1969b): Zur Histologie der Großhirnrinde von Balaenoptera borealis Lesson (Cetacea, Mysticeti); in Pilleri G (ed) Investigations on Cetacea. Berne, Institute of Brain Anatomy, vol 1, pp 151-170.

Ladygina TF, Supin AY (1970): The acoustic projection in the dolphin cerebral cortex. Fiziol Zh SSSR Im IM Sechanova 56:1554-1560.

Ladygina TF, Supin AY (1977): Localization of the projectional sensory areas in the cortex of the Atlantic bottlenose dolphin (Tursiops truncatus). Zh Evol Biokhim Fiziol 13:712718

Ladygina TF, Supin AY (1978): On homology of the different regions of the brain's cortex of cetacea and other mammals; in Sokolov VY (ed): Morskiye Mlekopitayushchiye: Resul'taty I Metody Issledovaniya. Moscow, Izdatel'stvo Nauka, pp 55-66.

Lende RA, Akdikmen S (1968): Motor field in cerebral cortex of the bottlenose dolphin. J Neurosurg 29:495-499. 
Lende RA, Welker WI (1972): An unusual sensory area in the cerebral neocortex of the bottlenose dolphin, Tursiops truncatus. Brain Res 45:555-560.

- Linden JF, Schreiner CE (2003): Columnar transformations in auditory cortex? A comparison to visual and somatosensory cortices. Cereb Cortex 13:83-89.

Lund JS (1973): Organization of neurons in the visual cortex, area 17, of the monkey (Macaca mulatta). J Comp Neurol 147:455-496.

Lund JS (1984): Spiny stellate neurons; in Peters A, Jones EG (eds): Cerebral Cortex Vol 1. Cellular Components of the Cerebral Cortex. New York, Plenum Press, pp 255-308.

-Lund JS, Boothe RG (1975): Interlaminar connections and pyramidal neuron organisation in the visual cortex, area 17, of the macaque monkey. J Comp Neurol 159:305-334.

-Manger PR (2006): An examination of cetacean brain structure with a novel hypothesis correlating thermogenesis to the evolution of a big brain. Biol Rev Camb Philos Soc 81:293338.

-Manger PR, Sum M, Szymanski M, Ridgway SH, Krubitzer LA (1998): Modular subdivisions of dolphin insular cortex: does evolutionary history repeat itself? J Cogn Neurosci 10: 153-166.

Marino L, Butti C, Connor RC, Fordyce RE, Herman LM, Hof PR, Lefebvre L, Lusseau D, McCowan B, Nimchinsky EA, Pack AA, Reidenberg JS, Reiss D, Rendell L, Uhen MD, Van der Gucht E, Whitehead H (2008): A claim in search of evidence: reply to Manger's thermogenesis hypothesis of cetacean brain structure. Biol Rev Camb Philos Soc 83:417-440.

-Matano S, Stephan H, Baron G (1985): Volume comparisons in the cerebellar complex of primates. 1. Ventral pons. Folia Primatol (Basel) 44:171-181.

-Morgane PJ, Glezer II, Jacobs MS (1988): Visual cortex of the dolphin: an image analysis study. J Comp Neurol 273:3-25.

Morgane PJ, Glezer II, Jacobs MS (1990): Comparative and evolutionary anatomy of the visual cortex of the dolphin; in Jones EG, Peters A (eds): Cerebral Cortex, Volume 8B: Comparative Structure and Evolution of the Cerebral Cortex, Part 2. New York, Plenum Press, pp 215-262.

Morgane PJ, Jacobs MS, Galaburda A (1986): Evolutionary morphology of the dolphin brain; in Schusterman R, Thomas J, Wood F (eds): Dolphin Cognition and Behavior: A Comparative Approach. Hillsdale, Erlbaum, pp 5-29.

- Morgane PJ, Jacobs MS, McFarland WL (1980): The anatomy of the brain of the bottlenose dolphin (Tursiops truncatus): surface configurations of the telencephalon of the bottlenose dolphin with comparative anatomical observations in four other cetacean species. Brain Res Bull 5:1-107.
Morgane PJ, Mc Farland WL, Jacobs MS (1982): The limbic lobe of the dolphin brain: a quantitative cytoarchitectonic study. J Hirnforsch 23:465-552.

Morisaka T, Connor RC (2007): Predation by killer whales (Orcinus orca) and the evolution of whistle loss and narrow-band high frequency clicks in odontocetes. J Evol Biol 20:1439-1458.

Nieuwenhuys R (1994): The neocortex: an overview of its evolutionary development, structural organization and synaptology. Anat Embryol (Berl) 190:307-337.

Nieuwenhuys R (1998): Telencephalon: in Nieuwenhuys R, ten Donkelaar HJ, Nicholson C (eds): The Central Nervous System of Vertebrates. New York, Springer, vol 3, pp 18712023.

Oelschläger, HHA (2008): The dolphin brain - a challenge for synthetic neurobiology. Brain Res Bull 75:450-459.

Oelschläger HHA, Oelschläger, JS (2002): Brain; in Perrin WF, Würsig B, Thewissen JGM (eds): Encyclopedia of Marine Mammals. San Diego, Academic Press, pp 133-158.

Oelschläger HHA, Oelschläger JS (2009): Brain; in Perrin WF, Würsig B, Thewissen JGM (eds): Encyclopedia of Marine Mammals. San Diego, Academic Press, ed 2, pp 134-149.

Oelschläger HHA, Ridgway $\mathrm{SH}$, Knauth M (2010): Cetacean brain evolution: dwarf sperm whale (Kogia sima) and common dolphin (Delphinus delphis) - an investigation with high-resolution 3D MRI. Brain Behav Evol 75:33-62. DOI: 10.1159/000293601.

Pakkenberg B, Gundersen HJG (1997): Neocortical neuron number in humans: effect of sex and age. J Comp Neurol 384:312-320.

Poth C, Fung C, Güntürkün O, Ridgway SH, Oelschläger HHA (2005): Neuron numbers in sensory cortices of five delphinids compared to a physeterid, the pygmy sperm whale. Brain Res Bull 66:357-360.

Revishchin AV, Garey LJ (1991): Laminar distribution of cytochrome oxidase staining in cetacean isocortex. Brain Behav Evol 37:355367.

Rice DW (1998): Marine Mammals of the World: Systematics and Distribution. Lawrence, The Society for Marine Mammalogy, 231 pp.

Ridgway, SH (1990): The central nervous system of the bottlenose dolphin; in Leatherwood S, Reeves RR (eds): The Bottlenose Dolphin. New York, Academic Press, pp 69-97.

Ridgway SH, Brownson RH (1984): Relative brain sizes and cortical surface areas in odontocetes. Acta Zool Fenn 172,149-152.

Rockel AJ, Hiorns RW, Powell TPS (1980): The basic uniformity in structure of the neocortex. Brain 103:221-244.

Schmitz C, Hof PR (2005): Design-based stereology in neuroscience. Neuroscience 130:813831.

- Schwerdtfeger WK, Oelschläger HA, Stephan H (1984): Quantitative neuroanatomy of the brain of the La Plata dolphin, Pontoporia blainvillei. Anat Embryol (Berl) 170:11-19.
Stephan H (1975): Allocortex; in Bargmann W (ed): Handbuch der mikroskopischen Anatomie des Menschen. Berlin, Springer, vol 4, pp 309-339.

Stephan H, Baron G, Frahm HD (1988): Comparative size of brains and brain components; in Steklis HD, Erwin J (eds): Comparative Primate Biology, vol 4, New York, Liss, pp 1-38.

Supin AY, Mukhametov LM, Ladygina TF, Popov VV, Mass AM, Poljakova IG (1978): Electrophysiological Studies of the Dolphin's Brain (in Russian). Moscow, Izdatel'stvo Nauka.

Supin AY, Popov VV, Mass AM (2001): The Sensory Physiology of Aquatic Mammals. London, Kluwer.

Tower DB (1954): Structural and functional organization of mammalian cerebral cortex: the correlation of neurone density with brain size. Cortical neurone density in the fin whale (Balaenoptera physalus L.) with a note on the cortical neurone density in the Indian elephant. J Comp Neurol 101:19-52.

Valverde F (1983): A comparative approach to neocortical organization based on the study of the brain of the hedgehog (Erinaceus europaeus); in Grisolia S, Guerri C, Samson F, Norton S, Reinoso-Suárez F (eds): Ramon y Cajal's Contribution to the Neurosciences. Amsterdam, Elsevier, pp 149-170.

Walloe S, Eriksen N, Dabelsteen T, Pakkenberg B (2010): A neurological comparative study of the harp seal (Pagophilus groenlandicus) and harbor porpoise (Phocoena phocoena) brain. Anat Rec (Hoboken) 293:2129-2135.

Wells RS, Scott MD (2009): Common bottlenose dolphin Tursiops truncatus; in Perrin WF, Würsig B, Thewissen JGM (eds): Encyclopedia of Marine Mammals, ed 2. San Diego, Academic Press, pp 249-255.

West MJ (1990): Stereological studies of the hippocampus: a comparison of the hippocampal subdivisions of diverse species including hedgehogs, laboratory rodents, wild mice and men. Prog Brain Res 83:13-36.

-West MJ, Slomianka L, Gundersen HJG (1991): Unbiased stereological estimation of the total number of neurons in the subdivisions of the rat hippocampus using the optical fractionator. Anat Rec 231:482-497.

White EL (1978): Identified neurons in mouse Sml cortex which are postsynaptic to thalamocortical axon terminals: a combined Golgi-electron microscopic and degeneration study. J Comp Neurol 181:627-661.

Wong-Riley M (1979): Changes in the visual system of monocularly sutured or enucleated cats demonstrable with cytochrome oxidase histochemistry. Brain Res 171:11-28.

Wong-Riley M, Carroll EW (1984): Effects of impulse blockage on cy tochrome oxidase activity in monkey visual system. Nature 307: 262-264.

Würsig B (2009): Playful behavior; in Perrin WF, Würsig B, Thewissen JGM (eds): Encyclopedia of Marine Mammals, ed 2. San Diego, Academic Press, pp 885-888. 